\title{
Detection of antimicrobial traits in fluorescent pseudomonads and molecular characterization of an antibiotic pyoluteorin
}

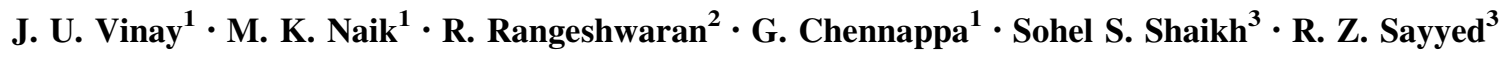

Received: 25 July 2016/ Accepted: 3 October 2016/Published online: 20 October 2016

(c) The Author(s) 2016. This article is published with open access at Springerlink.com

\begin{abstract}
Thirty isolates of fluorescent pseudomonads were obtained from rhizosphere of different crops in Raichur, India. The fluorescent pseudomonad strains were characterized in vitro for biochemical traits, antimicrobial traits, and pyoluteorin antibiotic production. All the isolates that showed fluorescent pigment production under UV light were rod shaped, Gram negative, positive for oxidase, catalase and citrate utilization tests, and negative for indole test. Out of 30 isolates, 07 isolates were positive for $\mathrm{HCN}$ production, 15 isolates were positive for $\mathrm{H}_{2} \mathrm{~S}$ production, and all the isolates were positive for siderophore production. Among all the isolates, RFP-22 showed the maximum percent inhibition of mycelium (46.66\%) of Rhizoctonia solani, the pathogen, and the remaining isolates showed the moderate to least inhibition of mycelium growth of $R$. solani. The $16 \mathrm{~S}$ rRNA analysis confirmed that the antibiotic positive isolates belonged to genus Pseudomonas. The amplification of 779 bp region in isolates RFP- 4 and RFP19 corresponded to pyoluteorin antibiotic-coding pltB gene. Further characterization of pyoluteorin antibiotic through TLC and TOF-MS analysis confirmed the presence of pyoluteorin at $274.26(\mathrm{~g} / \mathrm{mol})$ peak and $2.10 \mathrm{~min}$ retention time. Biochemical and molecular analyses confirmed the antagonism of Pseudomonas and isolate through pyoluteorin production.
\end{abstract}

R. Z. Sayyed

sayyedrz@gmail.com

1 Department of Plant Pathology, University of Agricultural Science, Raichur, India

2 Department of Microbiology, NBAIR, Bangalore, India

3 Department of Microbiology, PSGVP Mandal's, Shri S I Patil Arts, G B Patel Science and STSKVS Commerce College, Shahada Dist, Nandurbar, MS 425 409, India
Keywords Antibiotic - Fluorescent pseudomonads · Pyoluteorin · TLC · TOF-MS

\section{Introduction}

Some of the rhizobacteria positively influence on plant growth and health which were referred as Plant Growth Promoting Rhizobacteria (PGPR). These rhizobacteria are abundant in rhizosheric soil of several crops, and these maintained the ecological balance in niche needed for their survival. These PGPR played a pivotal role in both growth promotion and plant disease control. The mechanisms of growth promotion by these PGPRs are complex and appear to comprise both changes in the microbial balance in the rhizosphere and alterations in host plant physiology (Bashan and Bashan 2005). Biological control of diseases by plant growth promoting rhizobacteria was well-established phenomenon (Shaikh and Sayyed 2015; Shaikh et al. 2016). The antibiotics, $\mathrm{HCN}, \mathrm{H}_{2} \mathrm{~S}$, and siderophore have been shown to play a major role in the suppression of several plant pathogens (Handelsman and Stabb 1996; Shaikh et al. 2014).

Among rhizobacteria, Pseudomonas sp. are often used as model root-colonizing bacteria (Lugtenberg et al. 2001). The plant growth promoting strain fluorescent Pseudomonas are known to produce an array of antibiotics, such as 2,4-diacetylphloroglucinol (2,4-DAPG), pyoluteorin (PLT), pyrrolnitrin (PRN), phenazine-1-carboxyclic acid (PCA), 2-hydroxyphenazines, phenazine-1-carboxamide (PCN), rhamnolipids, oomycin A, cepaciamide A, ecomycins, viscosinamide, and karalicin which are capable of suppressing a broad spectrum of plant pathogens. Among them pyoluteorin, 2,4-DAPG and phenazine are major determinants in biocontrol activity (Borauh and Kumar 2002). 
Pyoluteorin was aromatic phenolic polyketide antibiotic that was first isolated from $P$. aeruginosa (Takeda 1958) and later from $P$. fluorescens strains $\mathrm{Pf}-5$ and $\mathrm{CHA} 0$ (Bencini et al. 1983). PLT has bactericidal, herbicidal, and fungicidal activities, in particular against Pythium spp. (Takeda 1958). Howell and Stipanovic (1980) first established the importance of pyoluteorin antibiotic production in suppression of seedling pathogens, such as Pythium ultimum, causing damping off in cotton using $P$. fluorescens pf-5. Similarly, the efficacy of $P$. fluorescens (Pf-5) could be improved by altering the expression of the pyoluteorin producing genes in such a way that effective concentrations of the antibiotic are reached in the seed spermosphere more quickly after a seed was planted (Kraus and Loper 1995). Genetic analysis of several Pseudomonas strains has also established a positive correlation between antibiotic production and disease suppression (Homma and Suzui 1989).

The present investigation is aimed at screening of pyoluteorin gene and antimicrobial traits in several fluorescent pseudomonad strains of different crop rhizospheres through PCR and to characterize pyoluteorin antibiotic through thin-layer chromatography and Time-of-FlightMass spectroscopy (TOF-MS).

\section{Materials and methods}

\section{Isolation and biochemical characterization of fluorescent Pseudomonas isolates}

Isolation of fluorescent Pseudomonas was carried out by serial dilution technique. The $0.1 \mathrm{ml}$ of $10^{-5}$ and $10^{-6}$ was placed on King's B medium to isolate the colonies. Plates were incubated at $28{ }^{\circ} \mathrm{C}$ for $48 \mathrm{~h}$. After incubation, wellseparated individual colonies with yellow green and blue white pigments were marked and detected by viewing under UV light.

Gram staining and pigment production in different isolates of fluorescent Pseudomonas was carried out according to the Laboratory Guide for Identification of Plant Pathogenic Bacteria published by the American Phytopathological Society (Schaad 1992).

Simmon's citrate agar medium was adjusted to $\mathrm{pH} 7.0$, and then, the slants were prepared. Culture was streaked in the slant. The citrate utilization positive reaction was indicated by the change in the colour of the media from green to Prussian blue (Simmons 1926).

Oxidase, catalase, and indole tests were also carried out as per the protocol given by Vanitha et al. (2009). The oxidase and catalase tests were carried out to confirm the aerobic nature of pseudomonads. In oxidase test, a culture grown for $24 \mathrm{~h}$ in NA supplemented with $1 \%$ glucose was used. Loopful cells were rubbed onto a filter paper impregnated with $1 \%$ (w/v) aqueous tetra-methyl-p-phenylene diamine dihydrochloride solution. A change in the colour of the cultures to deep purple within $10 \mathrm{~s}$ was registered as a positive result (Kovacs 1956). In catalase test, a loopful of $48 \mathrm{~h}$ growth of the test bacterium was smeared on a slide and was covered with few drops of hydrogen peroxide. The reaction was noticed as positive if gas bubbles were produced.

For indole test, tryptone broth was inoculated with a small amount of a pure culture of Pseudomonas sp. and incubated at $35{ }^{\circ} \mathrm{C}$ for $48 \mathrm{~h}$. Five drops of Kovac's reagent were added directly to the tubes to test the indole production. The reaction was noticed as positive if there is a formation of a pink-to-red colour in the reagent layer on top of the medium.

\section{Characterization of antimicrobial traits in fluorescent pseudomonads}

\section{Hydrogen sulfide test}

Bacterial isolates were stab inoculated to test tube containing the SIM agar medium and were incubated at $37{ }^{\circ} \mathrm{C}$ for $48 \mathrm{~h}$. Black colouration along the line of stab inoculation indicated positive reaction (Vanitha et al. 2009).

\section{Hydrogen cyanide production}

A strip of sterilized filter paper saturated with a solution containing picric acid, $0.5 \%$, and sodium carbonate (2.0\%) was placed inside the NA slants amended with glycine $(4.4 \mathrm{~g} / \mathrm{l})$ and $\mathrm{FeCl}_{3} \cdot 6 \mathrm{H}_{2} \mathrm{O}(0.3 \mathrm{mM})$ which were already inoculated with test bacteria and hermetic sealing was done. Change in colour of the filter paper from yellow to brown in 5 days was considered as positive reaction (Bakker and Schippers 1987).

\section{Siderophore production}

Siderophore production was determined by Chrome Azurol $\mathrm{S}$ (CAS) assay. The CAS agar medium was prepared according to procedure given by Schwayn and Neilands (1987). The bacterial culture streaked on the CAS plate. Change of medium colour to orange or presence of light orange halo surrounding the bacterial growth indicates siderophore production by the bacterial isolates. 
Screening of fluorescent pseudomonads for testing bioefficacy against Rhizoctonia solani by dual culture

The pseudomonads were streaked 1 day earlier to the test pathogen. They were incubated for control reaches periphery of plates. The diameter of the colony of the fungus was measured in both directions and average was recorded and the percent inhibition on growth of the test fungus was calculated using the formula given below by (Vincent 1927):

$I=\frac{C-T}{C} \times 100$

where $I=$ Percent inhibition, $C=$ Radial growth of fungus in control, and $T=$ Radial growth of fungus in treatment.

\section{Molecular characterization of pyoluteorin gene}

\section{Genomic DNA isolation}

The selected isolates were inoculated in the LB broth and kept overnight for incubation in a shaker at $150 \mathrm{rpm}$. The DNA was isolated from the selected isolates following procedure using HiPurA ${ }^{\mathrm{TM}}$ Bacterial and Yeast Genomic DNA Purification Spin Kit HIMEDIA.

\section{Molecular characterization of pyoluteorin gene through PCR}

The PCR reaction $(25 \mu \mathrm{L})$ consisted of $50 \mathrm{ng}$ of genomic DNA, $1 \times$ Taq DNA polymerase buffer, $0.5 \mathrm{U}$ of Taq DNA polymerase, $0.2 \mathrm{mM}$ of each dNTP, $1.5 \mathrm{mM} \mathrm{MgCl}_{2}$, and $50 \mathrm{~mol}$ of primers pltBf (CGGAGCATGGACCCCCAGC) and pltBr (GTGCCCGATATTGGT CTTGACCGAG). Amplification was performed in a DNA thermal cycler with the initial denaturation at $94{ }^{\circ} \mathrm{C}$ for $3 \mathrm{~min}, 30$ cycles of $94{ }^{\circ} \mathrm{C}$ for $60 \mathrm{~s}, 58{ }^{\circ} \mathrm{C}$ for $45 \mathrm{~s}$, and $72{ }^{\circ} \mathrm{C}$ for $60 \mathrm{~s}$ and final extension at $72{ }^{\circ} \mathrm{C}$ for $10 \mathrm{~min}$. Then aliquots of $10-15$ $\mu \mathrm{L}$ of each amplification product was electrophoresed on $0.8 \%$ agarose gel in $1 \times$ Tris-acetate-EDTA (TAE) buffer (40 mM Tris-acetate, $1 \mathrm{mM}$ EDTA, $\mathrm{pH} 8.0$ ) at $50 \mathrm{~V}$ for 1-3 $\mathrm{h}$ and stained with ethidium bromide and the PCR products were visualized under a UV transilluminator. Following this, $100 \mathrm{bp}$ ladder was used as size markers.

\section{Amplification and sequencing of $16 S$ rRNA gene}

Amplification of 16S rRNA gene from the genomic DNA of bacteria was carried out using universal primer set, forward primer fD1 (AGTTTGATCCTGGCTCA), and reverse primer rP2 (ACGGCTACCTTGTTACGACTT). PCR cocktail $(50 \mu \mathrm{l})$ contained $50 \mathrm{pM}$ of primer, $50 \mathrm{ng}$ of genomic DNA, 1X TaqDNA polymerase buffer, $1 \mathrm{U}$ of TaqDNA polymerase, $0.2 \mathrm{mM}$ of each dNTPs, and $1.5 \mathrm{mM}$ $\mathrm{MgCl}_{2}$. The thermal cycling program for the amplification of $16 \mathrm{~S}$ rRNA gene consisted of initial denaturation at $94{ }^{\circ} \mathrm{C}$ for $1 \mathrm{~min}, 30$ cycles of denaturation at $94{ }^{\circ} \mathrm{C}$ for $1 \mathrm{~min}$, annealing at $46^{\circ} \mathrm{C}$ for $30 \mathrm{~s}$, and extension at $72{ }^{\circ} \mathrm{C}$ for $4 \mathrm{~min}$ with a final extension at $72{ }^{\circ} \mathrm{C}$ for $10 \mathrm{~min}$. Amplification was performed in a DNA thermal cycler. A 5- $\mu$ l aliquot of each amplification product was electrophoresed on a $1.5 \%$ agarose gel in $1 \times$ TAE buffer at $50 \mathrm{~V}$ for $45 \mathrm{~min}$, stained with ethidium bromide and the PCR products were visualized with a UV transilluminator.

\section{Detection of pyoluteorin antibiotic through thin- layer chromatography (TLC)}

The pyoluteorin antibiotic production by strain of $P$. putida was determined using a modified method of Chang and Blackwood (1969). Bacterial culture was grown in $5 \mathrm{ml}$ of pigment production medium (peptone, $20 \mathrm{~g}$; glycerol, $20 \mathrm{ml} ; \mathrm{NaCl}, 5 \mathrm{~g} ; \mathrm{KNO}_{3}, 1 \mathrm{~g}$; distilled water, $1 \mathrm{l} ; \mathrm{pH}$ 7.2) for 4 days on a rotary shaker at room temperature $\left(28 \pm 2{ }^{\circ} \mathrm{C}\right)$. The culture was centrifuged at $3500 \mathrm{rpm}$ for $5 \mathrm{~min}$; the supernatant collected, acidified to $\mathrm{pH} 2$ with $1 \mathrm{~N}$ $\mathrm{HCl}$, and then extracted with an equal volume of ethyl acetate. The ethyl acetate extract was reduced to dryness in vacuo and the residue dissolved in methanol. Twenty microlitre samples was applied to thin-layer chromatography plates coated with a $250 \mu \mathrm{m}$ layer of silica gel and developed in chloroform and methanol $(9: 1, v / v)$ and benzene and acetic acid $(9.5: 0.5, v / v)$ for pyoluteorin as solvent system. The spots were visualized by spraying with diazotized sulphanilic acid or under UV at $254 \mathrm{~nm}$. $R f$ values of the spots were compared with synthetic antibiotics.

\section{Detection of pyoluteorin antibiotic through time-of- flight-mass spectroscopy}

The dried and purified antifungal metabolite was collected and crystallized by dissolving in ethyl acetate $(6 \mathrm{ml})$ and filtered to remove insoluble impurities. The filter was washed with ethyl acetate $(2 \mathrm{ml})$, and the wash was added to ethyl acetate solution. After leaving this solution over night at $-20{ }^{\circ} \mathrm{C}$, the crystals were collected. The crystallized antifungal metabolite was re-suspended in a minimum quantity of acetone and analyzed by mass spectroscopy and it was used to identify the retention time and molecular weight of antibiotic. 


\section{Results}

\section{Isolation and biochemical characterization of fluorescent Pseudomonas isolates}

Thirty fluorescent Pseudomonas isolates were collected from the rhizosphere soil of ground nut, pigeon pea, chick pea, sesame, tomato, chilli, sunflower, castor, maize, rice, ragi, niger, safflower, cowpea, horse gram, chrysanthemum, guar, soybean, Vinca rosea, and marigold from the farm of University of Agricultural Sciences, Raichur campus, and surrounding villages. In addition, some samples were also collected from Dharwad and Chitradurga. Isolation was done using King'B media by the serial dilution method.

All the isolates showed Gram-negative reaction and rod shape, and pigment production was seen in both Pseudomonas agar F medium and fluorescence under UV light that confirmed that all the isolates belong to fluorescent pseudomonads group. Further characterization of them revealed that all the isolates were positive for oxidase test, catalase test, and citrate utilization and were negative for indole test.

\section{Antimicrobial traits of fluorescent Pseudomonas isolates}

The fluorescent Pseudomonas isolates are known to produce many secondary metabolites, such as hydrogen cyanide $(\mathrm{HCN})$, hydrogen sulfide $\left(\mathrm{H}_{2} \mathrm{~S}\right)$, and siderophores which are antagonistic properties against many phytopathogens. Among 30 isolates, seven isolates RFP-3, RFP-5, RFP-14, RFP-19, RFP-20, RFP-21, and RFP-26 were positive for $\mathrm{HCN}$ production and 15 isolates were positive for $\mathrm{H}_{2} \mathrm{~S}$ production (Table 1).

All the isolates of fluorescent Pseudomonas sp. were shown positive for siderophore production on CAS agar medium which was indicated by production of yellow/orange-coloured zone surrounding the bacterial growth. Among 30 isolates, six isolates produced higher siderophore production ( $>4 \mathrm{~mm}$ orange colour zone), eight isolates produced moderate siderophore production (2-4 $\mathrm{mm}$ orange colour zone), and 16 isolates produced less siderophore production $(<2 \mathrm{~mm}$ orange colour zone) (Table 1).

\section{Screening of fluorescent pseudomonads for testing the bioefficacy against Rhizoctonia solani by dual culture}

Efficacy of 30 indigenous fluorescent pseudomonads was studied under in vitro by screening against Rhizoctonia
Table 1 Characterization of fluorescent pseudomonads isolates for antimicrobial traits

\begin{tabular}{|c|c|c|c|c|}
\hline Sl. no. & Isolates & $\mathrm{H}_{2} \mathrm{~S}$ production & $\mathrm{HCN}$ production & Siderophore* \\
\hline 1 & RFP-1 & Positive & Negative & Medium \\
\hline 2 & RFP-2 & Negative & Negative & Medium \\
\hline 3 & RFP-3 & Positive & Positive & Poor \\
\hline 4 & RFP-4 & Positive & Negative & Poor \\
\hline 5 & RFP-5 & Negative & Positive & Strong \\
\hline 6 & RFP-6 & Positive & Negative & Medium \\
\hline 7 & RFP-7 & Positive & Negative & Strong \\
\hline 8 & RFP-8 & Negative & Negative & Poor \\
\hline 9 & RFP-9 & Positive & Negative & Poor \\
\hline 10 & RFP-10 & Positive & Negative & Poor \\
\hline 11 & RFP-11 & Negative & Negative & Poor \\
\hline 12 & RFP-12 & Positive & Negative & Poor \\
\hline 13 & RFP-13 & Positive & Negative & Poor \\
\hline 14 & RFP-14 & Positive & Positive & Poor \\
\hline 15 & RFP-15 & Negative & Negative & Strong \\
\hline 16 & RFP-16 & Negative & Negative & Medium \\
\hline 17 & RFP-17 & Negative & Negative & Poor \\
\hline 18 & RFP-18 & Negative & Negative & Strong \\
\hline 19 & RFP-19 & Positive & Positive & Medium \\
\hline 20 & RFP-20 & Negative & Positive & Poor \\
\hline 21 & RFP-21 & Positive & Positive & Medium \\
\hline 22 & RFP-22 & Negative & Negative & Medium \\
\hline 23 & RFP-23 & Negative & Negative & Poor \\
\hline 24 & RFP-24 & Positive & Negative & Strong \\
\hline 25 & RFP-25 & Negative & Negative & Poor \\
\hline 26 & RFP-26 & Positive & Positive & Medium \\
\hline 27 & RFP-27 & Negative & Negative & Poor \\
\hline 28 & RFP-28 & Positive & Negative & Strong \\
\hline 29 & RFP-29 & Negative & Negative & Poor \\
\hline 30 & RFP-30 & Negative & Negative & Poor \\
\hline
\end{tabular}

* Orange colour zone, strong $>4 \mathrm{~mm}$, medium $2-4 \mathrm{~mm}$, poor $<2 \mathrm{~mm}$

solani using the dual culture method. The results on inhibition of mycelial growth of $R$. solani was recorded and presented here under. Among the isolates tested, RFP-22 showed the maximum percent inhibition of mycelium $(46.66 \%)$ and the second highest percent inhibition by RFP-6 (45.55\%), followed by RFP-19 (44\%), RFP-3 (44 \%), RFP-21 (43.33\%), and RFP-7 (42.22\%). The remaining isolates showed the moderate inhibition $R$. solani. The RFP-9 (16.66 \%) and RFP-17 (6.66 \%) showed least inhibition of pathogen (Table 2).

\section{Molecular characterization of pyoluteorin gene}

The fluorescent pseudomonads isolates were screened for pyoluteorin antibiotic gene through PCR using gene 
Table 2 In vitro efficacy of fluorescent pseudomonads isolates against $R$. solani, the causal agent of sheath blight of rice

\begin{tabular}{|c|c|c|}
\hline Sl. no. & Isolates & Percent inhibition \\
\hline 1 & RFP-1 & $37.22(37.43)$ \\
\hline 2 & RFP-2 & $35.00(36.08)$ \\
\hline 3 & RFP-3 & $44.00(41.37)$ \\
\hline 4 & RFP-4 & $37.77(37.56)$ \\
\hline 5 & RFP-5 & $37.77(37.56)$ \\
\hline 6 & RFP-6 & 45.55 (42.17) \\
\hline 7 & RFP-7 & $42.22(40.34)$ \\
\hline 8 & RFP-8 & $36.66(36.99)$ \\
\hline 9 & RFP-9 & $16.66(23.65)$ \\
\hline 10 & RFP-10 & $41.11(39.67)$ \\
\hline 11 & RFP-11 & 38.88 (38.26) \\
\hline 12 & RFP-12 & $38.88(38.26)$ \\
\hline 13 & RFP-13 & $34.44(35.24)$ \\
\hline 14 & RFP-14 & 36.66 (36.99) \\
\hline 15 & RFP-15 & $33.33(35.05)$ \\
\hline 16 & RFP-16 & $35.00(36.10)$ \\
\hline 17 & RFP-17 & $6.66(14.43)$ \\
\hline 18 & RFP-18 & 37.77 (37.66) \\
\hline 19 & RFP-19 & $44.00(41.37)$ \\
\hline 20 & RFP-20 & $41.11(39.67)$ \\
\hline 21 & RFP-21 & $43.33(41.00)$ \\
\hline 22 & RFP-22 & $46.66(42.83)$ \\
\hline 23 & RFP-23 & $21.11(27.24)$ \\
\hline 24 & RFP-24 & $30.00(33.04)$ \\
\hline 25 & RFP-25 & $40.00(39.11)$ \\
\hline 26 & RFP-26 & $41.66(39.86)$ \\
\hline 27 & RFP-27 & $35.55(36.25)$ \\
\hline 28 & RFP-28 & $32.22(34.36)$ \\
\hline 29 & RFP-29 & $32.77(34.63)$ \\
\hline 30 & RFP-30 & $28.66(33.17)$ \\
\hline \multirow[t]{3}{*}{31} & Control & 0.00 \\
\hline & $\mathrm{SEM} \pm$ & 0.52 \\
\hline & $\mathrm{CD}(P=0.01)$ & 2.03 \\
\hline
\end{tabular}

* Figures in the parentheses are arc sine values

specific primers pltC1, pltC2, pltBf, and pltBr. The isolates, namely, RFP- 4 and RFP-19, showed amplification of 779 bp region which corresponded to pyoluteorin antibiotic-coding pltB gene (Fig. 1). The remaining isolates did not show any amplification in this region of genome.

\section{The 16S rRNA amplification of pltB gene positive of fluorescent pseudomonads isolates}

The extracted DNA of pyoluteorin positive isolates (RFP-4 and RFP-19) were amplified with 16S rRNA universal primers $\mathrm{fD} 1$ and $\mathrm{rP} 2$. The two fluorescent pseudomonads

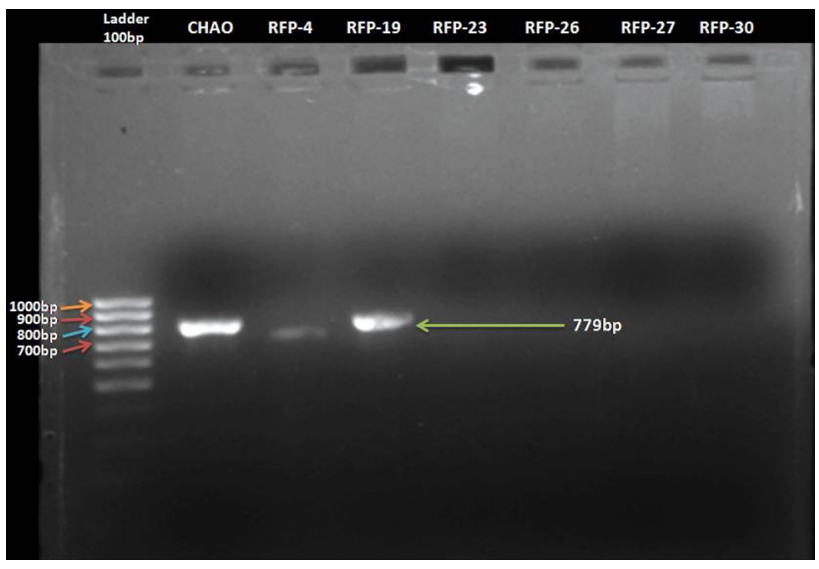

Fig. 1 Molecular detection of pyoluteorin (pltB) antibiotic gene in RFP-4 and RFP-19 strains of fluorescent pseudomonads

isolates were amplified and amplified product were checked on $1.5 \%$ agarose gel. The size of amplified DNA showed $1500 \mathrm{bp}$ in length. Sequencing and BLAST of them in NCBI revealed that both the isolates belonged to Pseudomonas putida.

\section{Detection of pyoluteorin antibiotic through TLC}

The antibiotic production was tested by growing the antibiotic positive strains in pigment producing medium and extracted with ethyl acetate. The production of pyoluteorin antibiotic in RFP-4 and RFP-19 strains was confirmed by TLC at $R f$ value 0.50 in TLC plate in chloroform: acetone $(9: 1 \mathrm{v} / \mathrm{v})$ solvent system. This was compared with the standard reference antibiotic which was comigrated with sample in TLC plate.

\section{Detection of pyoluteorin through time-of-flight-mass spectroscopy (TOF-MS)}

The pyoluteorin antibiotic extract of $P$. putida strain RFP-4 was analyzed through TOF-MS. The TOF-MS analysis of RFP-4 strain extract displayed 17 individual discrete chromatograms. These mass chromatograms showed 20 intense peaks at 227.12, 197.11, 158.07, 246.22, 245.11, $211.13,302.28,227.12,288.27,316.26,274.26,149.01$, $301.12,330.32,304.28,344.29,568.53,540.50,512.47$, and 484.44 (Fig. 2a, b). Many minor peaks also noticed in the chromatograms. In time-of-flight analysis, 17 different retention times $0.55,0.65,0.73,0.80,1.01,1.09,1.76,2.10$, $2.25,2.42,2.54,2.71,2.90,3.55,3.72,3.89$, and $4.13 \mathrm{~min}$ were obtained. Among different peaks and retention times, $274.26(\mathrm{~g} / \mathrm{mol})$ peak (Fig. 2c) and $2.10 \mathrm{~min}$ retention time (Fig. 3) indicate the presence of pyoluteorin antibiotic in the RFP-4 strain's antibiotic extract. 
a $_{1501138-S a m p l e-2} 48$ (0.830)
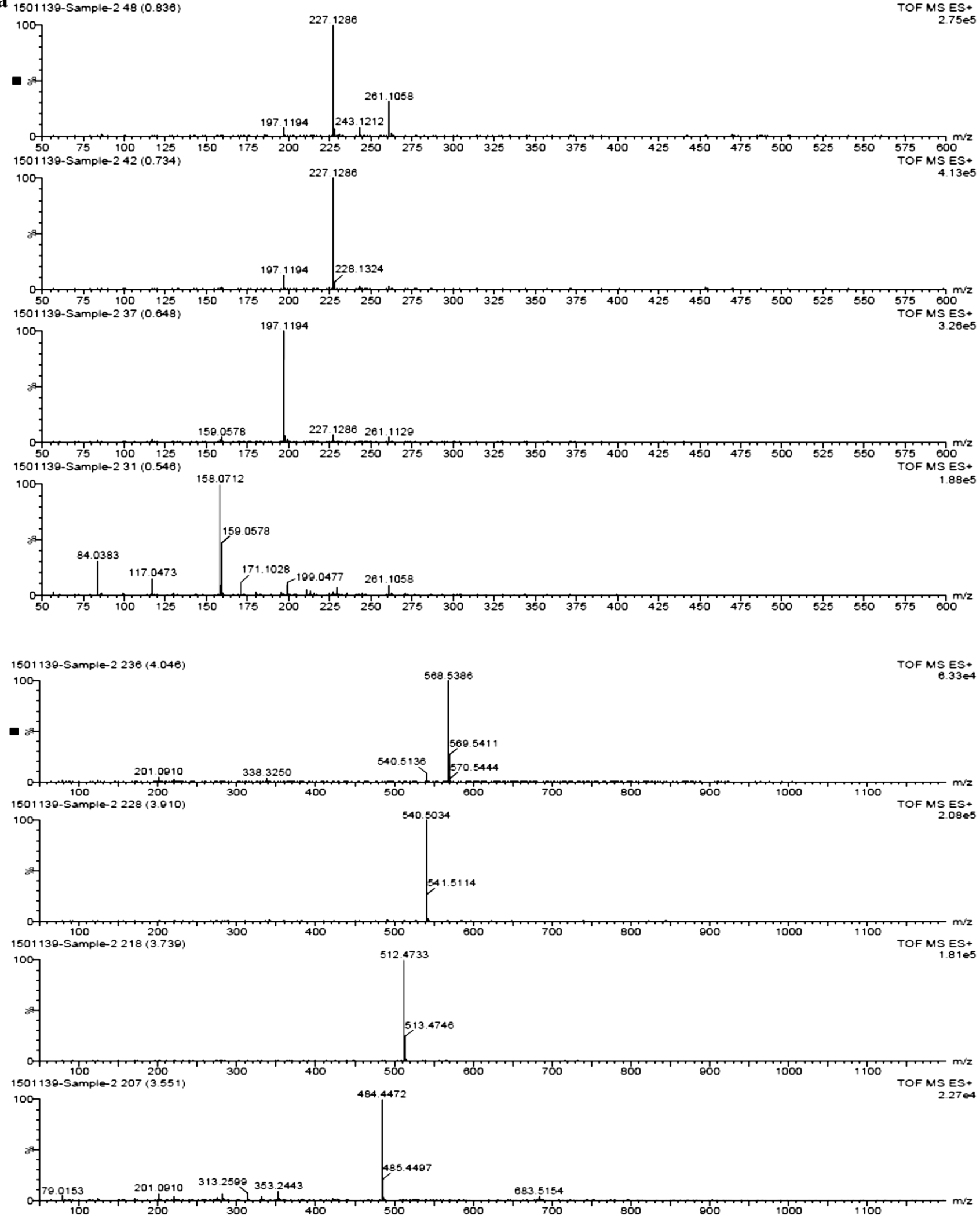

Fig. 2 a TOF-MS profiling of $P$. putida RFP-4 extract showing different peaks. b TOF-MS profiling of $P$. putida RFP-4 extract showing different peaks. c TOF-MS analysis of pyoluteorin antibiotic (RFP-4) showing peak at $274.26(\mathrm{~g} / \mathrm{mol})$ 


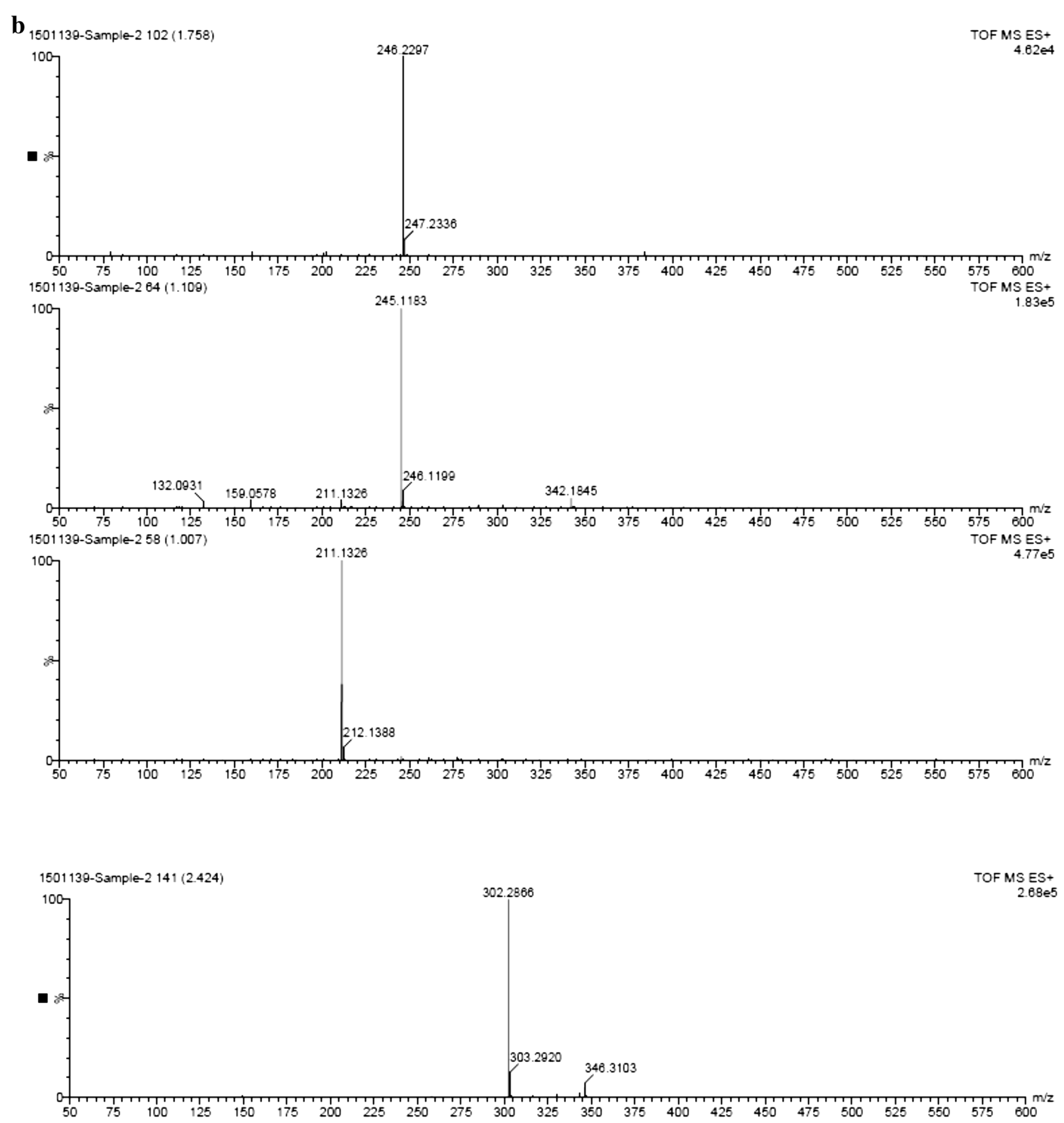

Fig. 2 continued

\section{Discussion}

In the era of soil pollution and pesticide resistance in agriculture, there is need of better substitute for agrochemicals. The next best choice was biological control in plant diseases. Therefore, necessity of selection of potential isolates with efficient secondary metabolites production was present target of many researcher's in the field of biological control. Due to failure of many pesticides in plant disease control, secondary metabolites of biocontrol agents, such as fluorescent pseudomonads, were future ecofriendly weapons in targeting the plant diseases due to antimicrobial characteristics of those metabolites. Therefore, identifying and retrieving of antimicrobial traits from fluorescent pseudomonads were done in the present investigations. 


\section{c}
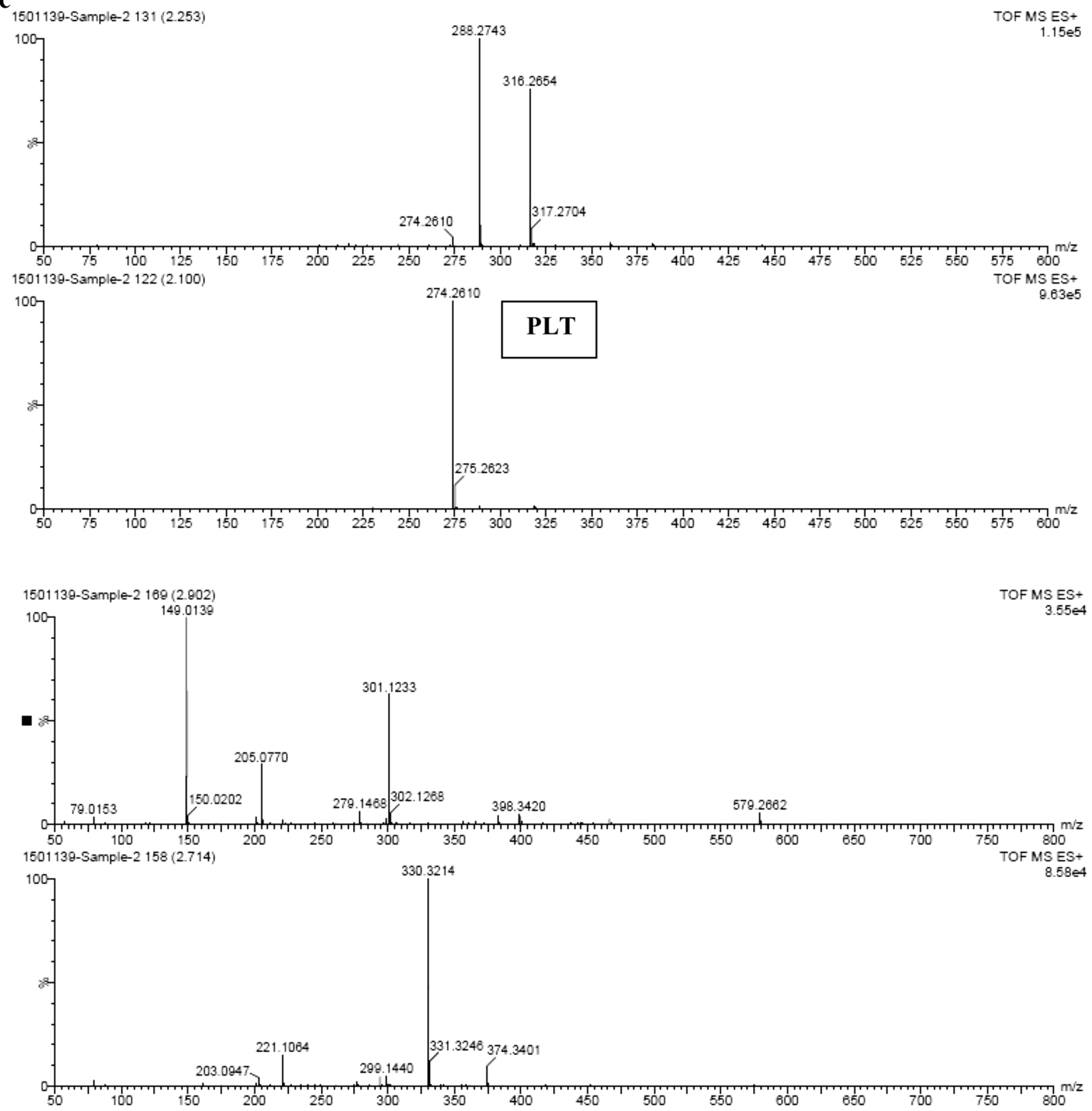

Fig. 2 continued

As an initial step in the identification and exploitation of bioagents, collection and characterization of fluorescent pseudomonad isolates were done from diverse niche of their survival, i.e., from different crop rhizospheres in Raichur, and some more additional isolates were also collected from Chitradurga and Dharwad for the comparison of nature and performance among isolates. In addition, characterization of these isolates was done and the result of identification of these isolates was compared with identification and screening for pgpr traits (Laha and Verma 1998; Omolola 2007; Meera and Balabaskar 2012; Manjunath et al. 2011; Deshwal and Kumar 2013).

The antimicrobial nature of these secondary metabolites was confirmed by Fiddaman and Rossall (1993) who reported the fungal cell-wall degradation activity of $\mathrm{HCN}$, 


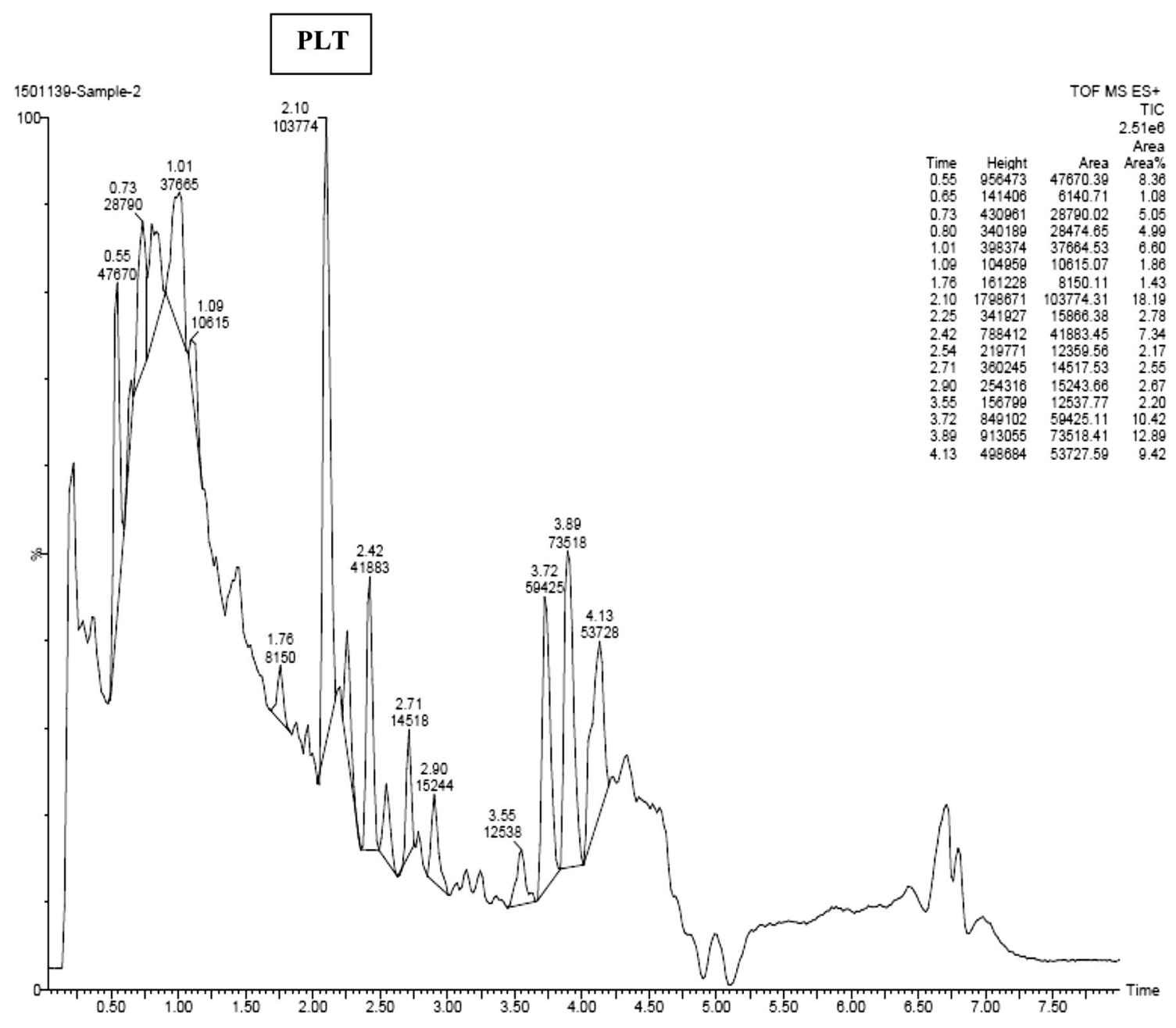

Fig. 3 TOF-MS analysis of pyoluteorin antibiotic (RFP-4) showing retention time at $2.10 \mathrm{~min}$

which was produced from Pseudomonas fluorescens. Manidipa et al. (2013) confirmed that production of antibiotics, siderophores, volatile compounds, hydrocyanic acid (HCN), enzymes, and phytohormones in Pseudomonas, effectively controlled the fungal and bacterial diseases of rice.

Screening of 30 fluorescent pseudomonads against $R$. solani, gifted a nine fruitful superior strains RFP-3, RFP-6, RFP-7, RFP-10, RFP-19, RFP-20, RFP-21, RFP-22, and RFP-26 which were showing more than $40 \%$ mycelial inhibition in dual culture technique.

The ten genes, pltA, $B, C, D, E, F, G, L, R$, and $M$, were required for the pyoluteorin biosynthesis by Pseudomonas fluorescens pf-5 (Nowak-Thompson et al. 1997). Each of these genes has their own pivotal role in biosynthesis of pyoluteorin (Nowak-Thompson et al. 1999). In the present investigation, pltB gene was detected using polymerase chain reaction (PCR) using the gene specific primers, pltBf and pltBr. Among 35 isolates of fluorescent pseudomonads, two isolates (RFP-4 and RFP-19) showed successful amplification at $779 \mathrm{bp}$ region in the genome of these isolates. That region corresponds to pltB gene, which encodes the biosynthesis of pyoluteorin antibiotic. The results are in correspondence to those Saikia et al. (2011) who reported that, out of the 25 isolates, pyoluteorin (PLT) antibiotic-coding gene was detected in the isolate, Pf373. The 779 bp gene (pltB) amplification was earlier reported by Naik et al. (2008) and Ashwitha et al. (2013).

Further identification of species of pyoluteorin positive fluorescent pseudomonads through 16S rRNA sequence analysis revealed that the two pyoluteorin positive isolates RFP- 4 and RFP-19 belong to Pseudomonas putida. The RFP-4 strain was isolated from groundnut rhizosphere, KVK, Raichur, and RFP-19 strain was isolated from tomato, Chandraband, Raichur. The RFP-22 strain showed maximum zone of inhibition against $R$. solani. This strain belongs to Pseudomonas putida which was isolated from sesamum rhizosphere, MARS, Raichur. 
Pyoluteorin antibiotic detection was done through TLC based on mobility of the compound on the silica plate that is measured in terms of retardation factor ( $R f$ value). The $R f$ value of 0.50 corresponded to pyoluteorin antibiotic with chloroform: acetone solvent system and confirmed the expression of PLT genes as detected earlier. The pyoluteorin antibiotic detected at based on $R f$ value $(0.50)$ by Cazorla et al. (2006), Ayyadurai et al. (2007) and Naik et al. (2008).

The TOF-MS characterization helped in identification of unknown metabolites in sample based on the peaks formed in chromatogram which was correspondent to molecular weight of that compound. In addition to that, retention time is also a key factor in identification of unknown compound. The TOF-MS analysis of RFP-4 strain antibiotic extract displayed 17 individual discrete chromatograms with different peaks and retention time. Among different peaks and retention time, $274.26(\mathrm{~g} / \mathrm{mol})$ peak and 2.10 min retention time confirmed the presence of pyoluteorin antibiotic in the RFP-4 strain. These mass chromatograms showed 20 intense peaks, several minor peaks, and different retention time, and indicated the presence of unknown secondary metabolites and splitting of ions from parent molecules in the P. putida RFP-4 extracted solvent. Some of the metabolites also noticed at undetectable level, which were showed minute peak in chromatograms.

The characterization of pyoluteorin antibiotic through PCR, chromatography, and TOF-MS helped in selection of pyoluteorin positive strains of fluorescent pseudomonads for future successful disease management, although pyoluteorin antibiotic was most effective against oomycete plant pathogens (Howell and Stipanovic 1980). The present investigation gifted superior fruitful strains of fluorescent pseudomonads from different crop rhizospheres. Among these, two strains were proved as pyoluteorin (pltB) positive with different stages of confirmation of pyoluteorin antibiotic production, which are gene level through PCR and its product level through TLC and TOF-MS.

Acknowledgments We are grateful to Nagaraj, Ph.D. scholar, University of Mysore, for their exemplary and unquantifiable effort in completing the chromatographic work.

\section{Compliance with ethical standards}

Conflict of interest All authors declare no conflict of interest.

Open Access This article is distributed under the terms of the Creative Commons Attribution 4.0 International License (http:// creativecommons.org/licenses/by/4.0/), which permits unrestricted use, distribution, and reproduction in any medium, provided you give appropriate credit to the original author(s) and the source, provide a link to the Creative Commons license, and indicate if changes were made.

\section{References}

Ashwitha K, Rangeshwaran R, Vajid NV, Sivakumar G, Jalali SK, Rajalaksmi K, Manjunath H (2013) Characterization of abiotic stress tolerant Pseudomonas sp. occurring in Indian soils. J Biol Control 27(4):45-48

Ayyadurai N, Naik PR, Sakthivel N (2007) Functional characterization of antagonistic fluorescent Pseudomonads associated with rhizospheric soil of rice (Oryza sativa L.). J Microbiol Biotechnol 17(6):919-927

Bakker AW, Schippers B (1987) Microbial cyanide production in the rhizosphere in relation to potato yield reduction and Pseudomonas sp. mediated plant growth stimulation. Soil Biol Biochem 19:451-457

Bashan Y, de Bashan LE (2005) Bacteria/plant growth-promotion. In: Hillel D (ed) Encyclopedia of soils in the environment, vol 1. Elsevier, Oxford, pp 103-115

Bencini DA, Howell CR, Wild JR (1983) Production of phenolic metabolites by a soil pseudomonad. Soil Biol Biochem 15:491-492

Borauh HPD, Kumar BSD (2002) Plant disease suppression and growth promotion by a fluorescent Pseudomonas strain. Folia Microbiol 47(2):137-143

Cazorla FM, Duckett SB, Bergstrom ET, Noreen S, Odijk R, Lugtenberg BJJ, Thomas-Oates JE, Bloemberg GV (2006) Biocontrol of Avocado dematophora root rot by antagonistic Pseudomonas fluorescens PCL1606 correlates with the production of 2-hexyl 5-propyl resorcinol. Mol Pl Microbe Interact 19(4):418-428

Chang PC, Blackwood AC (1969) Simultaneous production of three phenazine-1- carboxylic acid pigments by Pseudomonas aureofaciens. Can J Microbiol 15:439-444

Fiddaman PJ, Rossall S (1993) The production of antifungal volatiles by Bacillus subtilis. J Appl Bacteriol 74(2):119-126

Deshwal VK, Kumar P (2013) Effect of heavy metals on growth and PGPR activity of Pseudomonads and production of plant growth promoting substances by Pseudomonads. J Acad Indus Res 2(5):286-290

Handelsman J, Stabb EV (1996) Bio-control of soil borne plant pathogens. Plant Cell 8:1855-1869

Homma Y, Suzui T (1989) Role of antibiotic production in suppression of radish damping-off by seed bacterization with Pseudomonas cepacia. Ann Phytopathol Soc Jpn 55:643-652

Howell CR, Stipanovic RD (1980) Suppression of Pythiumultimum induced damping-off of cotton seedlings by Pseudomonas fluorescensand its antibiotic, pyoluteorin. Phytopathol 70:712-715

Kovacs N (1956) Identification of Pseudomonas pyocyanea by the oxidase reaction. Nature 1956(178):703

Kraus J, Loper E (1995) Characterization of genomic region required for production of the antibiotic pyoluteorin by the biological control agent Pseudomonas fluorescens. Appl Environ Microbiol 61:849-854

Laha GS, Verma JP (1998) Role of fluorescent Pseudomonads in the suppression of root rot and damping-off of cotton. Indian Phytopath 51:275-278

Lugtenberg BJJ, Dekkers L, Bloemberg GV (2001) Molecular determinants of rhizosphere colonization by Pseudomonads. Ann Rev Phytopathol 39:461-490

Manidipa R, Dutta SG, Venkata RC (2013) Pseudomonads: Potential biocontrol agents of rice diseases. Res J Agric Forestry Sci $1(9): 19-25$

Manjunath H, Naik MK, Rangeshavaran SV, Vagid NV (2011) Deposition of sequences of $P$. putida possessing 2,4-DAPG 
antibiotic gene. In NCBI, Gene bank Maryland, USA. www. ncbi.nlm.nih.gov

Meera T, Balabaskar P (2012) Isolation and characterization of Pseudomonas fluorescens from rice fields. Int J Food Agric Veterinary Sci 2(1):113-120

Naik PR, Sahoo N, Goswami D, Ayyadurai N, Sakthivel N (2008) Genetic and functional diversity among fluorescent Pseudomonads isolated from the rhizosphere of banana. Microb Ecol 56:492-504

Nowak-Thompson B, Gould SJ, Loper JE (1997) Identification and sequence analysis of the genes encoding a polyketide synthase required for pyoluteorin biosynthesis in Pseudomonas fluorescens Pf-5. Gene 204:17-24

Nowak-Thompson B, Chaney N, Wing JS, Gould SJ, Loper JE (1999) Characterization of the pyoluteorin biosynthetic gene cluster of Pseudomonas fluorescens Pf-5. J Bacteriol 181(7):2166-2174

Omolola O (2007) The isolation of Pseudomonas aeruginosa from septic sore using some biological tests. Int J Food Saf 13:188-190

Saikia R, Sarma RK, Yadav A, Bora TC (2011) Genetic and functional diversity among the antagonistic potential fluorescent Pseudomonads isolated from tea rhizosphere. Curr Microbiol 62:434-444

Schaad NW (1992) Laboratory guide for identification of plant pathogenic bacteria. In: Schaad NW (ed) The American Psychopathological Society, Minneapolis, USA, pp 89-94
Schwayn B, Neilands JB (1987) Universal chemical assay for the detection and determination of siderophores. Anal Biochem 160:47-56

Shaikh SS, Sayyed RZ (2015) Role of plant growth promoting rhizobacteria and their formulation in biocontrol of plant diseases. In: Arora NK (ed) Plant microbes symbiosis: applied facets, Springer, India, pp 337-351. doi: 10.1007/978-81-322-2068-8_18

Shaikh SS, Patel PR, Patel SS, Nikam SD, Rane TU, Sayyed RZ (2014) Production of biocontrol traits by banana field fluorescent pseudomonads and their comparison with chemical fungicides. Ind J Exp Biol 52(9):917-920

Shaikh SS, Sayyed RZ, Reddy MS (2016) Plant growth promoting rhizobacteria: a sustainable approach to agro-ecosytstem. In: Hakeem KR et al (ed), Plant, soil and microbes-interactions and implications in crop science. Springer international publishing AG, Switzerland, pp 181-201. doi: 10.1007/978-3-319-27455-3_10

Simmons JS (1926) A culture medium for differentiating organisms of typhoid-colon aerogenes group and for isolating certain fungi. J Inf Dis 1926(39):209

Takeda R (1958) Structure of new antibiotic, pyoluteorin. J Am Chem Soc 80:47-49

Vanitha SC, Niranjana SR, Mortensen CN, Umesha S (2009) Bacterial wilt of tomato in Karnataka and its management by Pseudomonas fluorescens. Bio-control 2009(54):685-695

Vincent JM (1927) Distortion of fungal hyphae in the presence of some inhibitors. Nature 159:850 